13

\title{
Люминесцентные хемосенсорные свойства комплексных соединений Еu(III)
}

\author{
(C) Н.В. Петроченкова ${ }^{1,2}$, А.Г. Мирочник ${ }^{1, \uparrow}$ \\ ${ }^{1}$ Институт химии Дальневосточного отделения РАН, \\ 690022 Владивосток, Россия \\ ${ }^{2}$ Морской государственный университет им. адм. Г.И. Невельского, \\ 690059 Владивосток, Россия \\ ؟e-mail: mirochnik@ich.dvo.ru
}

Поступила в редакцию 12.08.2019 г.

В окончательной редакции 12.08.2019 г.

Принята к публикации 26.09.2019 г.

Обнаружены люминесцентные хемосенсорные свойства карбоксилатодибензоилметанатов Еu(III). Показано, что взаимодействие комплексов $\mathrm{Eu}(\mathrm{III})$ с парами аммиака или метиламина приводит к увеличению интенсивности люминесценции $\mathrm{Eu}(\mathrm{III})$. Предложен механизм оптического отклика, связанный с взаимодействием между молекулами аналита и комплекса $\mathrm{Eu}(\mathrm{III})$ и блокированием процесса тушения люминесценции.

Ключевые слова: европий(III), карбоксилатодибензоилметанаты, люминесценция, хемосенсоры, аммиак, метиламин.

DOI: $10.21883 /$ OS.2020.01.48851.246-19

Потребность в сенсорах, контролирующих наличие экологически вредных паров летучих органических соединений, диктуется необходимостью постоянного мониторинга окружающей среды. В настоящее время проводятся интенсивные исследования в области разработки полифункциональных материалов, обладающих оптическими хемосенсорными свойствами [1]. Одним из перспективных классов соединений для получения оптических хемосенсоров являются лантанидсодержащие комплексные соединения, обладающие люминесцентными свойствами. Люминесцентные лантанидсодержащие комплексные соединения могут быть использованы в качестве оптических хемосенсоров для детектирования анионов, катионов, газов и т.д. [3-8].

Особый интерес для практического применения представляет разработка хемосенсорных систем для таких аналитов, как аммиак и летучие амины. Аммиак токсичен, утечки больших количеств аммиака в промышленности губительны для человека $[9,10]$. Биогенные и летучие амины часто образуются при разложении аминокислот в метаболических процессах. Их аномально высокие концентрации могут указывать на порчу пищевых продуктов $[9,11]$.

Карбоксилатодибензоилметанаты (КДМ) $\mathrm{Eu}(\mathrm{III})$ обладают уникальными оптическими и магнитными свойствами [12,13]. В продолжение наших работ [12-17] по исследованию оптических хемосенсорных свойств комплексов $\mathrm{Eu}(\mathrm{III})$ в настоящей работе представлены результаты исследований люминесцентных хемосенсорных свойств КДМ $\mathrm{Eu}(\mathrm{III})$ состава $\mathrm{Eu}(\mathrm{Dbm})_{2} \mathrm{Acid} \cdot n \mathrm{H}_{2} \mathrm{O}$, где $\mathrm{Dbm}-$ дибензоилметанат-ион, Acid - анион карбоновой кислоты: муравьиной $\left(\mathrm{Form}^{-}\right)$, уксусной $\left(\mathrm{Ac}^{-}\right)$, пропионовой $\left(\mathrm{Prop}^{-}\right)$, валериановой $\left(\mathrm{Val}^{-}\right)$, капроновой $\left(\mathrm{Kapron}^{-}\right)$, каприловой $\left(\mathrm{Kapril}^{-}\right)$, акриловой $\left(\mathrm{Acr}^{-}\right)$, метакриловой $\left(\mathrm{Macr}^{-}\right)$, трифторуксусной $\left(\mathrm{TFA}^{-}\right)$, коричной $\left(\mathrm{Cin}^{-}\right), \alpha-$ цианкоричной $\left(\mathrm{CN}-\mathrm{Cin}^{-}\right), \beta$-пиперонилакриловой $(\beta$-рір$\left.\mathrm{Acr}^{-}\right), n=0-1$.

\section{Экспериментальная часть}

КДМ Eu(Dbm $)_{2}$ Acid $\cdot n \mathrm{H}_{2} \mathrm{O}$ синтезировали по методике [12]. Растворяли при нагревании $0.0024 \mathrm{M} \mathrm{HDbm} \mathrm{в}$ $20 \mathrm{ml}$ этанола и приливали к $10 \mathrm{~mL}$ этанольного раствора $0.0012 \mathrm{M} \mathrm{Eu}(\mathrm{NO})_{3} \cdot 6 \mathrm{H}_{2} \mathrm{O}$. При постоянном перемешивании и слабом нагревании $\left(40-50^{\circ} \mathrm{C}\right)$ к полученному раствору по каплям добавляли $0.0012 \mathrm{M}$ кислоты. Реакционную смесь нейтрализовали спиртовым раствором аммиака до $\mathrm{pH}$ 8. Выпавший порошкообразный осадок отфильтровывали, промывали горячим этанолом, сушили на воздухе.

В качестве матрицы для иммобилизации КДМ Eu(III) использованы пластины для тонкослойной хроматографии ПТСХ-АФ-А фирмы Sorbfil. Затем образцы помещали в оптическую кювету с крышкой (толщина кюветы $1 \mathrm{~cm})$, в которую добавляли $0.05 \mathrm{~mL}$ водного раствора аммиака или метиламина (для создания определенного давления насыщенных паров аналита) [14].

Спектры люминесценции и возбуждения люминесценции образцов при $300 \mathrm{~K}$ регистрировали на спектрофлуориметре RF-5301 (Shimadzu). Спектры люминесценции образцов при $77 \mathrm{~K}$ регистрировали на спектрометре СДЛ-1. Источником возбуждения служила ртутная лампа ДРШ-250. 


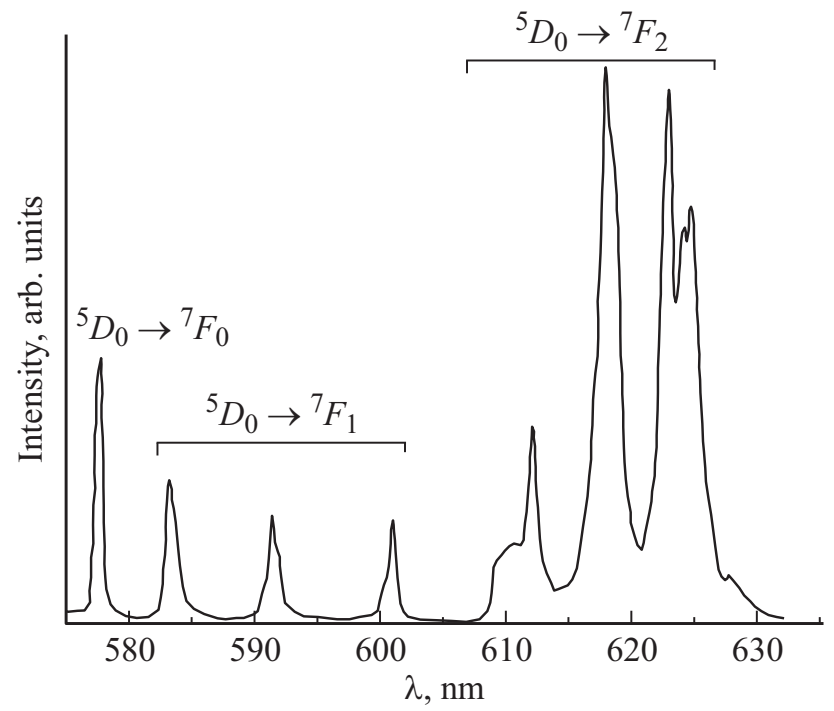

Рис. 1. Спектр люминесценции $\left(\lambda_{\text {возб }}=365 \mathrm{~nm}\right)$ соединения IV при $77 \mathrm{~K}$.

Люминесцентный оптический отклик КДМ Еu(III) (переход $\left.{ }^{5} D_{0}-{ }^{7} F_{2}\right)$ при воздействии паров аммиака и метиламина*

\begin{tabular}{r|l|c|c}
\hline \multirow{2}{*}{ № } & \multicolumn{2}{|c|}{ Соединение } & \multicolumn{2}{|c}{$\mathrm{I}_{0}$} \\
\cline { 3 - 4 } & & $\mathrm{NH}_{3}$ & $\mathrm{CH}_{3} \mathrm{NH}_{2}$ \\
\hline $\mathrm{I}$ & $\mathrm{Eu}(\mathrm{Dbm})_{3} 2 \mathrm{H}_{2} \mathrm{O}$ & 3.2 & 5.36 \\
\hline II & $\mathrm{Eu}(\mathrm{Dbm})_{2} \mathrm{Form}$ & 2.84 & 4.0 \\
\hline III & $\mathrm{Eu}(\mathrm{Dbm})_{2} \mathrm{Ac} \cdot \mathrm{H}_{2} \mathrm{O}$ & 5.76 & 3.88 \\
\hline IV & $\mathrm{Eu}(\mathrm{Dbm})_{2}$ Prop & 6.5 & 17.5 \\
\hline $\mathrm{V}$ & $\mathrm{Eu}(\mathrm{Dbm})_{2}$ Val & 16.7 & 21.3 \\
\hline $\mathrm{VI}$ & $\mathrm{Eu}(\mathrm{Dbm})_{2} \mathrm{Kapron}$ & 10.6 & 24.7 \\
\hline $\mathrm{VII}$ & $\mathrm{Eu}(\mathrm{Dbm})_{2} \mathrm{Kapril}$ & 10.3 & 19 \\
\hline $\mathrm{VIII}$ & $\mathrm{Eu}(\mathrm{Dbm})_{2} \mathrm{Acr}$ & 3.89 & 17.5 \\
\hline $\mathrm{IX}$ & $\mathrm{Eu}(\mathrm{Dbm})_{2} \mathrm{Macr} \cdot 0.5 \mathrm{H}_{2} \mathrm{O}$ & 1.9 & 5.8 \\
\hline $\mathrm{X}$ & $\mathrm{Eu}(\mathrm{Dbm})_{2} \mathrm{Cin} \cdot 0.5 \mathrm{H}_{2} \mathrm{O}$ & 1.75 & 20.3 \\
\hline $\mathrm{XI}$ & $\mathrm{Eu}(\mathrm{Dbm})_{2} \beta$-pip-Acr & 5.5 & 9.0 \\
\hline $\mathrm{XII}$ & $\mathrm{Eu}(\mathrm{Dbm})_{2}$ TFA $\cdot \mathrm{H}_{2} \mathrm{O}$ & 1.79 & 7.7 \\
\hline $\mathrm{XIII}$ & $\mathrm{Eu}(\mathrm{Dbm})_{2} \mathrm{CN}-\mathrm{Cin} \cdot 0.5 \mathrm{H}_{2} \mathrm{O}$ & 6.13 & 6.67 \\
\hline
\end{tabular}

Примечание. ${ }^{*} I_{0}$ - интенсивность люминесценции исходного образца.

\section{Результаты и обсуждение}

При облучении УФ светом полученные комплексы обладают интенсивной низкотемпературной люминесценцией, относительная интенсивность которой зависит от состава и строения лигандов. При переходе от 77 к $300 \mathrm{~K}$ наблюдается резкое уменьшение интенсивности люминесценции. По характеру спектров люминесценции исследуемые соединения можно разделить на две группы. К первой относятся комплексы III-XI (таблица), спектры люминесценции которых значительно отличаются (по характеру расщепления полос и распределения интенсивностей) от спектров большинства известных соединений $\mathrm{Eu}(\mathrm{III})$. При $77 \mathrm{~K}$ для спектров люминесценции этих соединений (рис. 1) характерна относительно высокая интенсивность полосы синглет-синглетного перехода ${ }^{5} D_{0}-{ }^{7} F_{0}$ по сравнению с ${ }^{5} D_{0}-{ }^{7} F_{2}$-переходом; штарковские компоненты перехода ${ }^{5} D_{0}-{ }^{7} F_{1}$ значительно удалены друг от друга; величина расщепления $\Delta F_{1}$ для данной группы комплексов составляет $490-540 \mathrm{~cm}^{-1}$.

Спектры люминесценции комплексов второй группы II, XII, XIII (таблица) сходны со спектрами большинства хелатов $\mathrm{Eu}(\mathrm{III})$ : основная доля энергии излучения приходится на переход ${ }^{5} D_{0}-{ }^{7} F_{2}$, интенсивность ${ }^{5} D_{0}-{ }^{7} F_{0}$ перехода незначительна (рис. 2). Величина $\Delta F_{1}$ для дан-

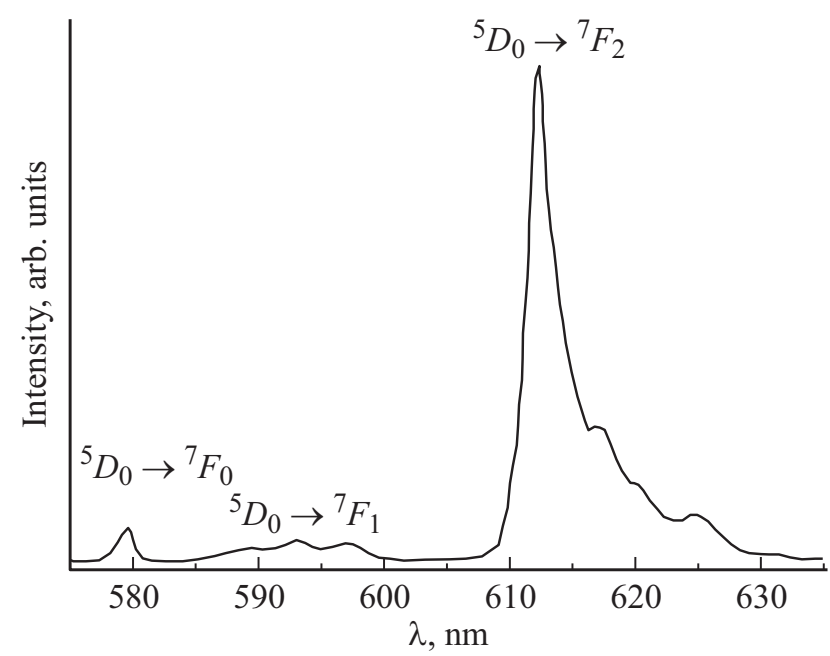

Рис. 2. Спектр люминесценции $\left(\lambda_{\text {возб }}=365 \mathrm{~nm}\right)$ соединения II при $77 \mathrm{~K}$.

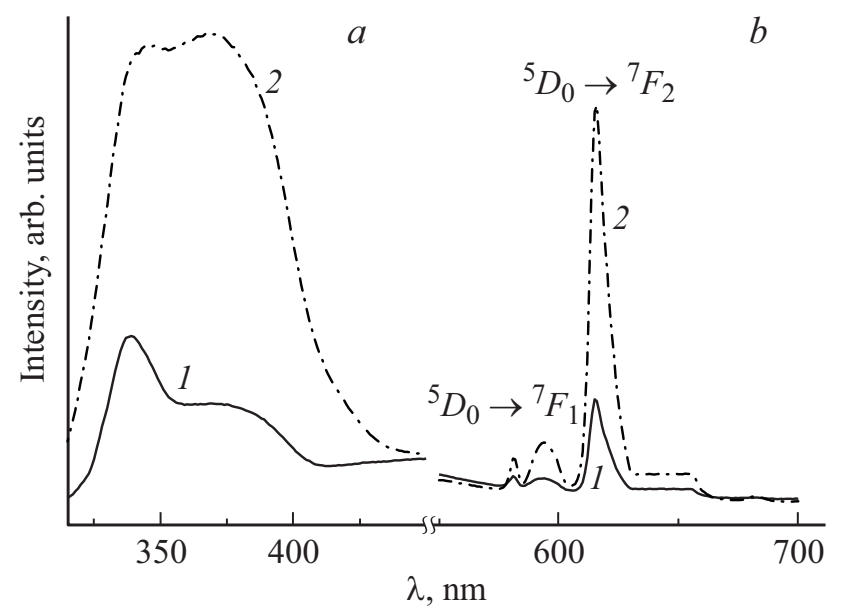

Pис. 3. Спектры возбуждения люминесценции (a) $\left(\lambda_{\text {лом }}=615 \mathrm{~nm}\right) \quad$ и $\quad$ люминесценции $\quad(b) \quad\left(\lambda_{\text {возб }}=370 \mathrm{~nm}\right)$ соединения IV, адсорбированного на силикагеле: исходный образец (1), в присутствии паров аммиака (2) при $300 \mathrm{~K}$. 


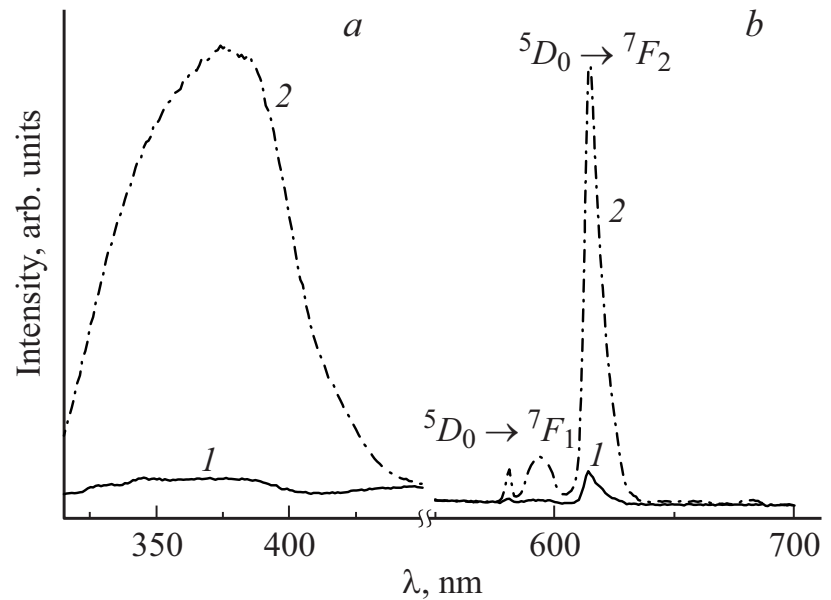

Pис. 4. Спектры возбуждения люминесценции (a) $\left(\lambda_{\text {люм }}=615 \mathrm{~nm}\right) \quad$ и люминесценции $\quad(b) \quad\left(\lambda_{\text {возб }}=370 \mathrm{~nm}\right)$ соединения IV, адсорбированного на силикагеле: исходный образец (1), в присутствии паров метиламина (2) при $300 \mathrm{~K}$.
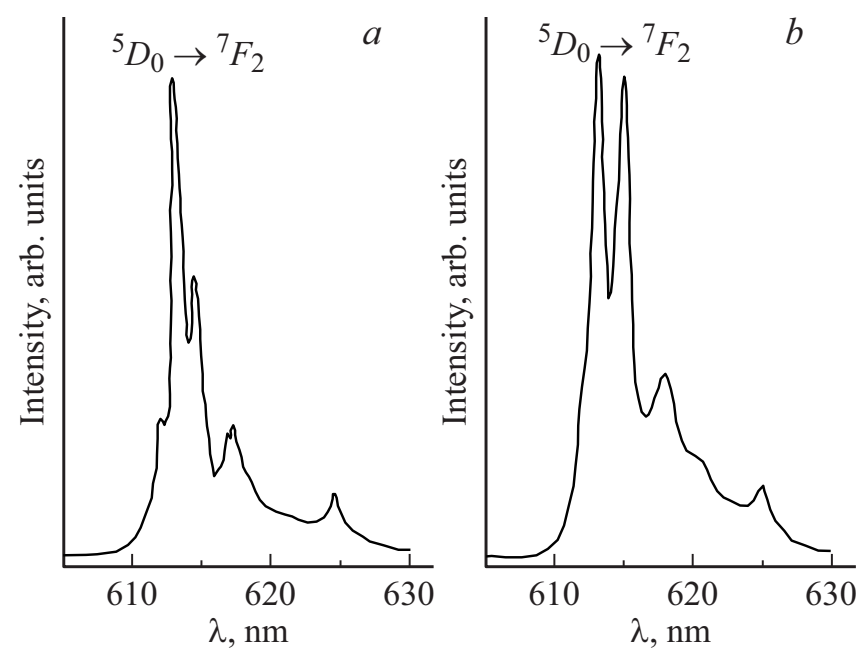

Рис. 5. Спектр люминесценции соединения IX при $77 \mathrm{~K}$ : исходный образец $(a)$, после обработки парами метиламина в течение $25 \min (b)\left(\lambda_{\text {возб }}=365 \mathrm{~nm}\right)$.

ной группы комплексов практически постоянна и составляет 200-225 $\mathrm{cm}^{-1}$. Следует отметить, что соединения второй группы обладают значительной люминесценцией и при $300 \mathrm{~K}$ в отличие от соединений первой группы, для которых характерно практически полное тушение люминесценции при комнатной температуре [12].

По данным большинства публикаций, посвященных хемосенсорным свойствам лантанидных комплексов при воздействии аналита на сенсор, как правило, регистрируется тушение люминесценции $\operatorname{Ln}(\mathrm{III})$ [18-20]. В случае исследуемых КДМ $\mathrm{Eu}(\mathrm{III})$ действие паров аммиака или метиламина приводит к заметному увеличению интенсивности люминесценции образцов (таблица).

При этом предельные расчетные концентрации насыщенных паров аммиака и воды над раствором составили
398000 и 14200 pрmv соответственно при нормальном атмосферном давлении и температуре $293 \mathrm{~K}$.

Как видно из данных таблицы, с увеличением длины углеводородного радикала карбоновой кислоты в целом наблюдается усиление люминесцентного отклика хемосенсора при воздействии аналитов. Наибольший люминесцентный отклик среди исследуемых соединений наблюдается для комплексов V-VII. Анализ данных таблицы также свидетельствует, что действие метиламина вызывает более эффективный люминесцентный отклик у исследуемых соединений.

О взаимодействии молекул аналита с координационной сферой $\mathrm{Eu}(\mathrm{III})$ свидетельствует заметное изменение спектров возбуждения люминесценции при комнатной температуре (рис. 3,4). При съемке спектров люминесценции при $77 \mathrm{~K}$ регистрируется изменение штарковской структуры спектров люминесценции $\mathrm{Eu}(\mathrm{III})$ при взаимодействии с аналитом (рис. 5). Обращает внимание то, что заметное изменение штарковской структуры спектров люминесценции при $77 \mathrm{~K}$ наблюдается в основном для соединений первой группы.

Возможным механизмом сенсибилизации люминесценции $\mathrm{Eu}(\mathrm{III})$ при воздействии паров аналита является возникновение связей между молекулами аналита и комплексом и, как следствие, блокирование процесса тушения люминесценции $\mathrm{Eu}(\mathrm{III})$.

Полученные люминесцентные хемосенсорные композиции на основе комплексных соединений европия перспективны для мониторинга окружающей среды и медицины.

\section{Финансирование работы}

Работа выполнена при финансовой поддержке Российского фонда фундаментальных исследований, проект № 19-03-00409.

\section{Конфликт интересов}

Авторы заявляют, что у них нет конфликта интересов.

\section{Список литературы}

[1] Hи Z., Deibert B.J., Li J. // Chem. Soc. Rev. 2014. V. 43. N 16. P. 5815. doi $10.1039 / \mathrm{c} 4 \mathrm{cs} 00010 \mathrm{~b}$

[2] Aletti A.B., Gillen D.M., Gunnlaugsson T. // Coord. Chem. Rev. 2018. V. 354. P. 98. doi 10.1016/j.ccr.2017.06.020

[3] Gunnlaugsson T., Pope S.J.A. // Luminescence of Lanthanide Ions in Coordination Compounds and Nanomaterials / Ed. by de Bettencourt-Dias A. John Wiley \& Sons Ltd., 2014. P. 231.

[4] Shuvaev S., Starck M., Parker D. // Chem. Eur. J. 2017. V. 23. P. 9974. doi 10.1002/chem.201700567

[5] Zhou J.-M., Shi W., Li H.-M., Li H., Cheng P. // J. Phys. Chem. C. 2014. V. 118. P. 416. doi 10.1021/jp4097502

[6] Mahata P., Mondal S.K., Singha D.K., Majee P. // Dalton Transactions. 2017. V. 46 (2). P. 301. doi 10.1039/C6DT03419E 
[7] Xu H., Cao C., Kang X., Zhao B. // Dalton Trans. 2016. V. 16. P. 18003. doi 10.1039/C6DT02213H

[8] Aulsebrook M.L., Graham B., Grace M.R., Tuck K.L. // Coord. Chem. Rev. 2018. V. 375. P. 191. doi 10.1016/j.ccr.2017.11.018

[9] Lawrence S.A. Amines: Synthesis, Properties, and Applications. Cambridge: Cambridge University Press, 2004. $371 \mathrm{pp}$.

[10] Timmer B., Olthuis W., Berg A. // Sens. Actuators. B. 2005. V. 107. P. 666. doi 10.1016/j.snb.2004.11.054

[11] Nakamura M., Sanji T., Tanaka M. // Chem. Eur. J. 2011. V. 17. P. 5344. doi 10.1002/chem.201003285.

[12] Карасев В.Е., Петроченкова Н.В., Мирочник А.Г., Петухова М.В., Лифар Л.И. // Коорд. химия. 2001. Т. 27. № 10. C. 790; Karasev V.E., Petrochenkova N.V., Mirochnik A.G., Petukhova M.V., Lifar L.I. // Rus. J. Coord. Chem. 2001. V. 27. N 10. P. 746.

[13] Ткаченко И.А., Петроченкова Н.В., Мирочник А.Г., Карасев В.Е., Кавун В.Я. // Журн. физ. хим. 2012. Т. 86. № 4. C. 765; Tkachenko I.A.; Petrochenkova N.V.; Mirochnik A.G., Karasev V.E., Kavun V.Ya. // Russ. J. Phys. Chem. 2012. V. 86. N 4. P. 681.

[14] Петроченкова Н.В., Мирочник А.Г., Шишов А.С., Сергеев А.А., Вознесенский С.С. // Журн. физ. хим. 2014. T. 88. № 1. C. 126; Petrochenkova N.V., Mirochnik A.G., Shishov A.S., Sergeev A.A., Voznesenskii S.S. // Russ. J. Phys. Chem. A. 2014. V. 88. P. 158.

[15] Mirochnik A.G., Petrochenkova N.V., Shishov A.S., Bukvetskii B.V., Emelina T.B., Sergeev A.A., Voznesenskii S.S. // Spectrochim. Acta. A. 2016. V. 155. P. 111. doi 10.1016/j.saa.2015.11.004

[16] Voznesenskiy S.S., Sergeev A.A., Mirochnik A.G., Leonov A.A., Petrochenkova N.V., Shishov A.S., Emelina T.B., Kulchin Yu.N. // Sensors and Actuators. B: Chem. 2017. V. 246. N 7. P. 46. doi 10.1016/j.snb.2017.02.034

[17] Petrochenkova N.V., Mirochnik A.G., Emelina T.B., Sergeev A.A., Leonov A.A., Voznesenskii S.S. // Spectrochim. Acta. A. 2018. V. 200. P. 70. doi 10.1016/j.saa.2018.03.084

[18] Mu Y., Ran Y., Du J., Wu X., Nie W., Zhang J., Liu H. // Polyhedron. 2017. V. 124. P. 125. doi 10.1016/j.poly.2016.12.030

[19] Mahata P., Mondal S.K., Singh D.K., Majee P. // Dalton Trans. 2017. V. 46. N 2. P. 301. doi 10.1039/c6dt03419e

[20] Wang W., Yang J., Wang R., Zhang L., Yu J., Sun D. // Crystal Growth \& Design. 2015. V. 15. N 6. P. 2589. doi 10.1021/acs.cgd.5b00381 